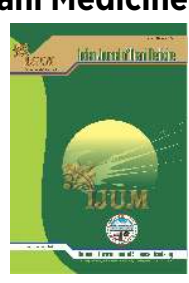

\title{
A SIMPLIFIED LITERATURE-BASED REVIEW: PHYTOCHEMISTRY, PHARMACOLOGY, SAFETY PROFILE, NUTRITIONAL VALUE AND TRADITIONAL THERAPEUTIC EFFECTS OF NIGELLA SATIVA L. IN UNANI SYSTEM OF MEDICINE.
}

\author{
Shaheen Akhlaq ${ }^{1 *}$, Shabnam Anjum Ara ${ }^{1}$, Mohammad Fazil', \\ Usama Akram ${ }^{3}$, Bilal Ahmad ${ }^{3}$, Merajul Haque ${ }^{3}$, Ahmad Sayeed ${ }^{3}$ and Asim Ali Khan ${ }^{4}$ \\ ${ }^{1}$ Senior Research Fellow, Hakim Ajmal Khan Institute for Literary \& \\ Historical Research in Unani Medicine, New Delhi, India \\ ${ }^{2}$ Incharge, Hakim Ajmal Khan Institute for Literary \& \\ Historical Research in Unani Medicine, New Delhi, India \\ ${ }^{3}$ Research officer, Hakim Ajmal Khan Institute for Literary \& \\ Historical Research in Unani Medicine, New Delhi, India \\ ${ }^{4}$ Director General, Central Council for Research in Unani Medicine, New Delhi, India
}

Review Paper

Received: 30.09.2021

Revised: 10.10.2021

ABSTRACT

Background: Nigella sativa L. or black cumin, belong to the family Ranunculaceae, has long been used traditionally, for food purposes and in traditional Unani medicines and is a native of the Arabian Gulf region, East Asia, Africa and Europe. It is a rich medicinal plant in bioactive compounds. Aim of the study: The aim of this review is to develop an overview of black cumin seed in the context of the status traditional Unani medicine ideology with the incorporation of ethno pharmacological uses, chemical compositions, pharmacological activities, safety profile with evidence-based approach. Materials and Methods: Information on Nigella sativa L. was obtained from published materials, including medicinal plants monographs, ancient and modern recorded classical texts, Unani pharmacopoeias and electronic databases such as Pub Med, Web of Science, Science Direct and Google Scholar. Results: Black cumin seed has been used in Unani traditional medical systems throughout history. The presence of thymoquinone is mainly responsible for its most of the medicinal properties. Moreover, the presence of vitamins, myristic acid, proteins, fats, fiber, amino acids and some trace metals are also reported in the seeds particularly used as a nutraceutical. Numerous in vivo and in vitro studies on pharmacological effects of Nigella sativa L. viz. antioxidant, anticancer, immuno-modulatory, antimicrobial, neuroprotective, cardio protective, gastro protective, anti-hypertensive, nephroprotective, hepatoprotective and anti-diabetic properties demonstrated positive effect against diabetes, hypertension, hypercholesterolemia, bronchitis, asthma, rheumatism, back pain, cancer, gastrointestinal disorders, and eczema etc. Conclusion: Contemporary researches on Nigella sativa L. support the views of Unani physicians for its use as a food and medicinal herb. Black cumin-based potential therapeutic agents need to be applied for a variety of diseases and the formulation of accepted functional foods with the aim to promote optimum health and lessen the risk of chronic diseases.

No. of Pages: 12

No. of Tables: 1

No. of Figures: 1

References: 59

Keywords: Unani Medicine, Anti-inflammatory, Diabetes mellitus, Nigella sativa L.

*Corresponding author: shazy123654@gmail.com 


\section{INTRODUCTION}

With the progress of in the important area of optimum nutrition, nowadays there is a renewed interest in the use of plants as a potent source for food as well as medicine ${ }^{1}$. In recent years, the concept of functional foods or nutraceuticals have gained popularity as they preserve health and protect against numerous ailments by providing basic nutritional demands, thus increase the average life expectancy. Herbs and spices are among the chunk of functional food materials such as, cumin, black cumin, cardamom etc. which are generally used as flavoring additives and preservatives in cooking that contain loads of bio functional molecule with enormous health-promoting prospective $^{2}$. The usage of medicinal plants has historically been used to improve health outcomes. The data of the World Health Organization (WHO) showed that more than threefourths of the population relied upon the medicinal plants for their primary health care needs due non affordability of allopathic medicines in resource-limited countries ${ }^{1}$. The reason lies in the fact that herbs, plant extracts and animaloriginated drugs are cheap, inexpensive and easily obtained thus acting against widespread pathogens ${ }^{3}$.

One of these medicinal plants is black seed, kalonji, shoneez or Nigella sativa L. which is a popular medicinal herb cum food in Unani system of medicine (one of the systems in AYUSH, whose theories laid on the teachings of the great Hippocrates known as the Father of medicine) ${ }^{4}$. The Prophet Mohammad had described the herb as universal healer as it provides protective as well as therapeutic benefits against multiple diseases ${ }^{5}$. Black Seed is also described in the Holy Bible as the curative black cumin, as Melanthion by Hippocrates (460-370 BC) as well as Dioscorides and as Gith near to Plin ${ }^{6}$. The seeds have been used broadly over 1400 years for culinary and therapeutic purposes in Indian and Middle Eastern cuisines. The seeds are described to be aromatic and bitter in taste ${ }^{7}$.

\section{Ethnopharmacological Aspects in Unani medicine Synonyms of Nigella sativa L.}

English: Black cumin, small fennel, Fennel flower, Love-ina-mist, Nutmeg flower, Devil in the Bush, Damascena; Arabic: Habat ut Barakah; Shonēz; Habbat-us-sauda; Kamūn-e-asvad; Persian: Siyāhdanah; Hindi: Kalonji, Kalājira; Sanskrit: Sthula Jiraka, Krishana -Jiraka, Upakunchika, Kālājājee, Sushavē, Ajaji, Kalvanjika, Kalika; Bengali: Mungrela; Tamil: Karun shiragam; Telugu: Peeajila Karra, Nallajilakara; Urdu: Kalonji ${ }^{8,9,10,11,121314}$.

\section{Plant Description}

Macroscopic feature of plant: It is a perennial, flowering plant with 30-60 cm height. Leaves are 2-3 in number, linear, pinnatisect $(2.5-5 \mathrm{~cm})$ and has tapering root; the flowers are white, yellow, pale blue color, with 5-10 petals on single long peduncle; sepals are acute, ovate, and clawed. A fruit capsule composed of united follicles (3-7), each including black seeds $(0.2 \mathrm{~cm} \times 0.1 \mathrm{~cm})$ which are dicotyledonous, angular, trigonous, rigose, flattened, oblong, funnel shaped, tubercular having rough testa of white kernel; Seeds produce lemon like slightly aromatic odor when crushed and bitter in taste. The seed coat is rough, thin measuring about $0.3 \mathrm{~mm}$ thick. Flowering and fruiting take place from January to April and is nurture in dry temperate regions in month of November till April ${ }^{8,9,10,15,16}$.

Microscopic feature of plant: On transverse section, seed coat is differentiated into testa and tegmen. The outermost layer is elliptical and single layer of epidermis with thickwalled cells enveloped by papillose cuticle packed with reddish-brown content which is followed by epidermis of (23) layers of thick-walled, parenchymatous cells, tangentially elongated up to pigmented layer; next to seed coat lies the endosperm that externally lines by thin layer epidermis and composed of fairly thick-walled rectangular to polygonal

\section{Nigella sativa L. (whole plant, seed capsule and seeds)}

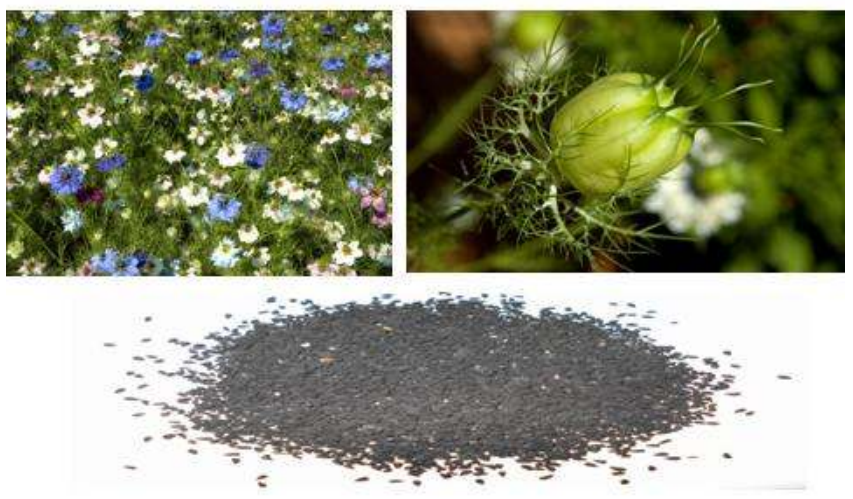

Figure 1: Various parts of Nigella sativa L.

Temperament

Hot and Dry in second degree ${ }^{9,10,14,15}$ Hot and Dry in third degree $^{5,11}$.

\section{Part Used and Dose}

Dried fruits ${ }^{13}$ and seeds are mainly used with dose of 1$2 \mathrm{~g}^{14,16}, 2.25-7 \mathrm{~g}^{9}$.

\section{Adverse Effects}

Harmful to liver (particularly hot temperament), kidneys, lungs ${ }^{9,10}$ and pharynx, if used in larger quantity causes diphtheria, syncope and even death ${ }^{10,14}$.

\section{Correctives}

Cucumis sativus (Tukhme Khyaar) ${ }^{9,10}$ Sterculia urens (Kateera) $^{10,14,15}$ Drugs of cold temperament (Cold 
temperamental articles) ${ }^{14}$ Bumbusa arundinacea (Banslochan) ${ }^{10,15}$, Vinegar, Cichorium intybus ${ }^{9,10,14}$.

\section{Substitute}

Resin of Olea europeae (olives) ${ }^{9,10}$ Lepidium sativum (Tukhme Rashaad), Pimpinella anisum in three parts of Hyoscyamus niger (Seeds of Ajwain Khurasani), and Anethum sowa (Sowa Seeds) (,10,11,14,15 $^{\text {. }}$

\section{Standardization profile}

Foreign organic matter

Purity

Total ash

Acid-insoluble Ash

Alcohol-soluble extractive

Water-soluble extractive

Solid Content
: Not greater than 2\%

: $94.5 \%$

: Not greater than 6\%

: Not greater than $0.2 \%$

: Not greater than 20\%

: Not greater than $15 \%$

$76.66 \%$

Table 1: Thin Layer Chromatography ${ }^{15}$

\begin{tabular}{|l|l|l|l|}
\hline S. No. & Extract Use & Solvent & Rf values \\
\hline 1 & Petroleum ether & Ether: Petroleum ether (1:4) & $0.95,0.89,0.22,0.15$ \\
\hline 2 & Petroleum ether & Benzene: Chloroform (3:5) & $0.97,0.89,0.84,0.60$ \\
\hline 3 & Chloroform & Ether: Petroleum ether (1:4) & $0.89,0.25,0.18,0.13$ \\
\hline 4 & Chloroform & Benzene: Chloroform (3:5) & 0.60 \\
\hline 5 & Acetone & Cloroform & $0.98,0.09$ \\
\hline 6 & Acetone & Toluene: Ethyl formate: Formic acid $(5: 4: 1)$ & \\
\hline
\end{tabular}

\section{Phytochemistry}

Nigella sativa L. seeds contain protein (26.7\%), fat (28.5\%), carbohydrates (24.9\%), crude fibre (8.4\%), and total ash (4.8\%). Its seeds also contain good amounts of various vitamins and minerals like $\mathrm{Cu}, \mathrm{P}, \mathrm{Zn}$, and Fe. Many active compounds have been identified in Nigella sativa L. $^{18}$. The presence of quinone constituent which is also known as thymoquinone (TQ) (30-48\%) is mainly responsible for its therapeutic properties ${ }^{19}$. Other constituents found are $p$ cymene (33-38\%), $\alpha$-thujene (6\%), carvacrol (1.3-1.4\%), dehydro-sabina ketone (4.4-4.5\%), camphene (11\%), $\alpha$ pinene $(1.11 \%)$, sabinene (1\%), $\beta$-pinene (7\%), $\alpha$ phellandrene $(0.45 \%), \quad \beta$-myrcene $(0.21 \%), \quad \gamma$-terpinene $(5.12 \%)$, limonene $(0.13 \%)$, camphor $(1 \%)$, terpinolene $(0.23 \%)$, thymol $(10.1 \%)$, carvone $(0.32 \%)$, t-anethol (1$4 \%)$, 4-terpineol (2-7\%), longicyclene (0.9\%), and sesquiterpene longifolene ${ }^{20}$. The essential oil from seeds comprised of nigellone and 2-methyl-4-isopropyl-quinone. The oil contains carvone (45-60\%), d-limonene and cymene. The fatty acids containing seeds include palmitic, myristic, stearic, oleic, linoleic and linolenic and Beta-sitosterol ${ }^{12}$. The nutritional composition revealed the presence of proteins (20-85\%), fats (38.20\%), fiber (7-94\%), total carbohydrates (31.94\%), major amino acids (glutamate, arginine, and aspartate) minor amino acids (cysteine and methionine), iron, copper, zinc, calcium, niacin, folic acid, phosphorus, thiamine and pyridoxine ${ }^{21}$.

Here, we review the existing literature critically on the pharmacological properties and health proceeds of black cumin and TQ and discuss the reported underlying molecular methods. We also address the safety issues related to remedial uses of black cumin.

\section{Methodology}

The information related to Nigella sativa L. was surveyed using bibliographic search. Urdu and Arabic version of Unani classical texts were analyzed. A thorough analysis of Botanical and English names of medicinal plants was done by Indian Medicinal Plants ${ }^{22}$ and different indexed journals. Books of modern scientific based, pertinent articles, periodicals, and peer reviewed indexed journals found on Pub Med, Science Direct, and Scopus were collected. The keywords Nigella sativa L., Unani medicine, antiinflammatory etc. were used for the searching of the contents.

\section{RESULTS AND DISCUSSION}

\section{Pharmacological Actions}

Mudirr-i-Haiz (Emmenagogue), Mowallid-i-Labn (Galactagogue), Mudirr-i-Baul (Diuretic), Muqawwi-iMe'dah (Stomachic), Munzij (Coctive), Jali (Detergent), Muharrik(Stimulant), Mulayyin-i-Shikam (Laxative), Kasire-Riyāh (Carminative), Mushtahi (Appetizer), Qatil-eDeedan-e-Am'a (Antihelminthic), (Anti-inflammatory), Daf'e Kharish (Anti-pruritic), Mu'arriq (Diaphoretic), Mukhaddir (Anaesthetic), Mujaffif (Dessicant), Musqit-eJaneen (Abortifacient), Naf'e Ziabetus (Antidiabetic), Daf'e sartān (Anticarcinogenic), Musakkin (Sedative), Musakkini-Alam (Analgesic), Muqawwi-i-Kabid (Hepatoprotective), 
Muqaww-e- Kuliya (Nephroprotective), Muqawwi-e-Aa'sab (Neuroprotective), Mufatteh Sudud (Deobstruent), Daf'e Humma (Anti- pyretic), Daf'e Su'al (Anti tussive), Mufattite Hasaat (Lithotryptic), Qatil-e-Jaraseem (Anti-microbial) $8,9,10,11,121314$

\section{Therapeutic effects described in Unani medicine}

Kalonji when used either singularly or combined with other drugs is beneficial in skin disorders such as scabies (Jarb), ringworm (Qooba), baldness (Sa'afa), vitiligo (bars), acne (busoor-i- labnia), wound healing etc. ${ }^{9,10,11}$. In boils, it heals the wounds when powdered seeds applied locally. Seeds are carminative, stimulant, diuretic, lactiferous, emmenagogue (stimulate uterine contractions). Fumigation and administration of pessary (paste made by mixing kalonji and oil of Iris encata) per vaginally promotes abortion. It is utilized for regulating menstrual disorders such as amenorrhea and uterine pain through oral intake of decoction or powdered kalonji seeds mixed with honey and cow ghee. Externally, cold and catarrh can be treated by snuffing of roasted seeds tied in muslin cloth, fumigation and as a nasal drop by combination of powdered seeds with olive oil. Internal consumption of powdered seeds treats asthma ${ }^{9,10,11,14}$. If powdered seeds in the dose of $4.5 \mathrm{~g}$ taken orally, it helps in the management of respiratory infections viz. bronchial asthma, orthopnoea (if taken with Borax), bronchitis, chest pain, halitosis ${ }^{9}$. Paste prepared of kalonji and vinegar used as nasal drop treats migraine and chronic headache. Application as paste treats poisoning; while used as liniment relieves tumours (Sulaa) and ptylosis (Intishar e Shaar). When kalonji is mixed with honey or hot water is used it help in expelling stones from kidney and bladder and thus relieves renal pain. Application of kalonji oil as nasal drops or massaging on affected parts, cure Paralysis (Falij), Bell's palsy, tremors, numbness and Tetanus ${ }^{9,10,11,14}$. It also used to kill and expel intestinal worms when used either externally or internally. Application of paste of powdered seeds mixed in juice of hanzal (Cochicium autumnale) or drmana (Artemesia meritima L.) on the umbilical and periumbilical region; or oral intake of powdered seeds ( $4.5 \mathrm{~g}$ ) with juice of Afsantīn (Artemisia absinthium) help in the excretion of worms. Inadequate lactation can be treated by prolonged intake of kalonji. Instillation of nasal drop made by powdered seeds in Roghan e Irsa (Iris encata) or its antimony help in curing eye diseases like cataract. Fumigation of seeds repels insects ${ }^{9,10,11,14}$. A tincture made from the seeds is beneficial in indigestion, diarrhea, and loss of appetite, dropsy, amenorrhea, intestinal worms and skin eruptions. The oil acts as an antiseptic and anesthetic on local application. It stops vomiting and nausea if, roasted black seeds are given internally. When applied as a paste of leaves, branches and seeds of kalonji cures the septic wounds over the genital region ${ }^{10,17}$. Nigella sativa $L$. is employed in
Moroccan folk medicine for the management of diabetes mellitus ${ }^{18}$. It is also used in puerperal diseases such as fever, loss of appetite and deranged secretions after delivery and tertian fever. If $4.5 \mathrm{~g}$ kalonji along with sikanjabeen (a type of syrup made of vinegar) consume, relieves insect bites ${ }^{9,12,13}$. Kalonji oil is a potent aphrodisiac, increases libido immensely if taken orally with olive oil and kundur (Bosewellia serrata). External use of paste cures piles ${ }^{9}$.

Ethno botanical uses indicates black cumin when used in the form of paste, essential oil, powder, and extract, treat many diseases, such as nasal congestion, asthma, bronchitis, rheumatism, toothache, headache, back pain, cancer, gastrointestinal disorders, eczema, and hypertension etc. Additionally, Nigella sativa L. seeds can heal muscle fatigue, depression and increase vitality of the body ${ }^{3}$.

\section{Ethnopharmacological prescriptions of kalonji}

- Ibn baitar (1197-1248AD) mentioned if a paste made by mixing kalonji with vinegar, applied on skin cures acne vulgaris, boils and resolves inflammation. Roasted seeds when mixed with Roghan e Susan (Iris ensata oil) or wax or Roghan e Hina (oil of Lawsonia inermis L.) to treat ptylosis, Da'al-Tha'lab (alopecia areata) and heals wound when applied in combination with rose water ${ }^{11}$.

- Azam Khan (1815-1902 CE) elaborated the use of kalonji oil as a liniment to treat Da'al-Tha'lab (alopecia areata). Application of liniment prepared by mixing kalonji seeds and vinegar treat tinea, leucoderma and pitryasis alba; or when applied by mixing in bol e tifl (childhood urine) alleviate disseminated warts, ulcers (cold or wet temperament). Any kind of alopecia (falling of hair from scalp) and ulcers can be treated by applying liniment of powdered roasted seeds with vinegar, honey, urine and rose water. Application of nasal drop (qutoor) through mixing of kalonji (seven in number) with mother's milk cures Jaundice ${ }^{9}$.

- Kabeeruddin (1889-1976 CE) mentioned if the paste prepared by soaking kalonji in vinegar and then grinded, applied on scalp treats quba (tinea) ${ }^{14}$.

- Najmul Ghani (1859 CE) advocated the use of kalonji act as a clearing agent (jali) when used as liniment (when prepared from ghee) for improving skin complexion through the clearing of impurities from skin. Another remedy for skin diseases particularly for leprosy can be treated through massaging skin, if oil prepared by mixing kalonji (46.64 g), Babchi (Psoralea corylifolia) (58.3 g), Dār hild (Curcuma longa L.) (58.3 g) and sulphur (23.32 g) soaked in coconut oil and placed in sunlight for seven days. In case of dog-bite it acts as an excellent antidote, if taken as a roasted powder after soaking in vinegar and then consumed in $7 \mathrm{~g}$ dosage for 
three days. Intake of powdered kalonji seeds and butter, each 3 gm treat hiccups. Likewise, ingestion of powder of kalonji seeds in a dose of $0.91-1.25 \mathrm{~g}$ treats dysmenorrhea $^{10}$.

- In Qarabadeen-e-Qadri, a famous Unani book of formulations of Unani drugs, it has been mentioned that kalonji seeds, dry ginger, Adhatoda vasica (arusa), root of Aplotaxis auriculata and Fagonia arabica L. (Badavard) each $3 g$ in the form of sugar candy relieves dyspnoea ${ }^{13}$.

\section{Unani formulations containing kalonji \\ Habb-e-Hilteet, Jawarish Shoneez, Majoon Fanjnosh, Majoon Kundur, Majoon Kalkalanaj ${ }^{14,15,16}$.}

\section{Pharmacological activities}

Numerous activities of Nigella Sativa L. have been investigated a list of few been described below.

\section{Antibacterial effect}

Topozada et al. (1965) were the first who reported the antibacterial activity of the phenolic fraction of Nigella sativa $L$. oil ${ }^{23}$. The antibacterial activity was accessed through a modified paper disc diffusion method on the seeds. At a concentration of $300 \mathrm{mg} / \mathrm{ml}$ a clear inhibition of the growth of Staphylococcus aureus was found, while distilled water taken as control and Azithromycin as positive control. Thymoquinone and melanin were the two important active ingredients responsible for antibacterial effect ${ }^{24}$. A clinical trial study was conducted on 40 icteric newborns (23 males, and 17 females, aged between 6-11 days) with pustular infection, without systemic involvement. Topical application of Nigella sativa was done in the experimental group $(n=20)$ and Mupirocin $(n=20)$ in the control group each for thrice daily on the skin lesions for 4 days. Results showed Nigella sativa L. extract inhibit staphylococcal pustular skin infections, similar to topical mupirocin ${ }^{25}$. Microbial resistance to drugs is an emerging issue. In vitro, studies indicated that many multi-drug-resistant gram positive and gram-negative bacteria showed potent antibacterial effects against resistant microorganisms, including resistant $S$. aureus and $P$. aeruginosa ${ }^{26}$.

\section{Antifungal effect}

The ether extract of Nigella sativa L. seed and its bioactive component thymoquinone against griseofulvin were tested against dermatophytes (eight species) with four species of Trichophyton rubrum and Trichophyton mentagrophytes, Trichophyton interdigitale, Epidermophyton floccosum and Microsporum canis with each one in number through the process of Agar diffusion method. It was incubated at $30^{\circ} \mathrm{C}$ for 14 days. The minimum inhibitory concentration of thymoquinone $(40 \mathrm{mg} / \mathrm{ml})$ and the ether extract $(0.125$ to $0.25 \mathrm{mg} / \mathrm{ml}$ ) showed to inhibit the growth of most of the dermatophytes by $80-100 \%$. The greater effect of thymoquinone than Nigella sativa $L$. ether extract represented the predominant effect of thymoquinone responsible for its antifungal activity ${ }^{27}$. In an experimental study, contaminated Candida albicans suspension acrylic resin were randomly alienated into six sets and treated with $0.2,0.4,20$, and $200 \mathrm{mg} / \mathrm{ml}$ of Nigella sativa L., nystatin (100,000 units) taken as positive control while distilled water as negative control for 8 hours and cultured in Sabouraud Dextrose Agar. The average number of colonies obtained were 122.6, 117.8, 73.4, and 14.4 colonies, as compared to distilled water (141.6) and nystatin (0) showing the effectiveness of Nigella sativa L. extract at high concentrations against C. albicans ${ }^{28}$.

\section{Antiviral effect}

In a study, when intra peritoneal administration of Nigella sativa $L$. oil was given to infected mice with murine cytomegalovirus for a period of 10 days, the virus was found undetectable in the spleen and liver, while it was detectable in the control mice. This action was attributed towards the increased number and function of M-phi, CD4 +ve T cells, suppressor function and increased production of INF-gamma ${ }^{29}$. Moreover, in a study of hepatitis $\mathrm{C}$ virus infected patients ( $\mathrm{n}=$ 30, 16 males and 14 females) who were not suitable for interferon IFN- $\alpha$ therapy, had received the capsule of NSO (450 $\mathrm{mg}$ ) for three consecutive months, for three times in a day after meals with follow up every two weeks. The findings suggested significant decreased of the viral load and improved laboratory parameters improved such as total protein (7.1 \pm 0.7 vs $7.5 \pm 0.8)$, albumin ( $3.5 \pm 0.87$ v. $3.69 \pm 0.91)$, red blood cell count (4.13 \pm 0.9 v. $4.3 \pm 0.9)$, and platelet count (167.7 \pm 91.2 v. $198.5 \pm 103)$. Fasting blood glucose $(104.03 \pm 43.42$ v. $92.1 \pm$ $31.34)$ and postprandial blood glucose (143.67 $\pm 72.56 \mathrm{v} .112 .1$ \pm 42.9 ) in HCV patients ${ }^{30}$.

\section{Antiparasitic effect}

In a recent study, the Schistosoma mansoni infected mice, when treated with Nigella sativa $L$. seed oil showed decreased burden of total worms. The number of deposited eggs was decreased significantly in the liver of mice. Fecundity of female $S$. mansoni also decreased with the loss of spines in tubercles and damaged tegmental surface showing the potency of Nigella sativa L. ${ }^{31}$. Further, the methanolic extract of Nigella sativa L. seeds $(1.25 \mathrm{~g} / \mathrm{kg})$ suppressed the infection of Plasmodium yoelii (94\%, $P<0.05$ ) whereas chloroquine (drug of choice) produced $86 \%$ of the infection. It was found that so, the methanolic extract of Nigella sativa $L$. seeds were more effective than chloroquine in treating parasitic infection thereby, improving the oxidative condition in red blood cells and hepatocytes ${ }^{32}$.

\section{Wound healing}

In vitro study model of aqueous extract of Nigella sativa L. with human gingival fibroblast as a monolayer, displayed a 
low free radical scavenging activity and induced gingival fibroblast proliferation $\left(\mathrm{EC}_{50}\right.$ of $22.6 \mu \mathrm{g} / \mathrm{mL}$ ) with hastened wound closure activity. Elevation of basic fibroblast growth factor and transforming growth factor beta was found ${ }^{33}$.

\section{Anti-inflammatory effect Psoriasis}

In context to the anti-inflammatory effect, in vivo study on the ethanolic extract of Nigella sativa L. seeds was conducted on mouse tail model and in vitro utilizing human keratinocyte cell lines through sulforhodamine B assay. The ethanol extract of Nigella sativa L. showed epidermal differentiation in the range of $71.36 \pm 2.64 \%$ while in the negative control it was $17.30 \pm 4.09 \%$ and in the positive control (tazarotene $0.1 \%$ ) was $90.03 \pm 2.00 \%$ with $\mathrm{IC}_{50}$ value of $239 \mu \mathrm{g} / \mathrm{ml}^{34}$. Jawad et al. (2014) evaluated the effect of different preparations of Nigella sativa L. in psoriasis treatment of alienated three groups in a trial. In the first group Nigella sativa L. ointment applied topically (10\% w/w, twice daily), the second group received crude pulverized plant (capsules with $500 \mathrm{mg}$ thrice daily), whereas the third group took the mixture of both treatments for 12 weeks. The inspected reaction has been reached total healing of psoriatic lesions (65\%) and a relapse rate (31\%) after cessation of treatment for four weeks. Oral doses of Nigella sativa L. showed good response $(50 \%)$ of patients, with a relapse rate $(50 \%)$ of patients. The combination of oral doses and ointment found the best results with total cure of lesions, and good responses (85\%) of patients, with a relapse rate $(18 \%)^{35}$.

\section{Acne vulgaris}

In a single blinded random controlled therapeutic study of diagnosed acne vulgaris patients $(n=93$, females $=53$, males $=$ 42) were enrolled with the age ranged between 13-23 years. The patients were alienated into 2 groups; group A (47 patient) used Nigella sativa L. oil lotion two times daily for 2 months, while group B (46 patient) used a control solution. Nigella sativa L. oil lotion found to reduce $10 \%$ mean lesion count of papules and pustules after 2 months of therapy. The response to treatment was ranked as good (58\%), moderate (35\%) and no response (7\%) in the test group, while the satisfaction of patients from the treatment was found to be full (67\%), partial (28\%), and no satisfaction (5\%). In the control group the lesions showed no significant reduction after 2 months, and the response to treatment was good (8\%), moderate (34\%), and no response (58\%) while the satisfaction of patients with treatment in was full (8\%), partial (24\%), and no satisfaction (68\%). No reported adverse effects were found in the group treated with $10 \%$ of Nigella sativa L. oil lotion. The authors accredited the results to the immunomodulatory, antimicrobial, and antiinflammatory effects of Nigella sativa L. oil ${ }^{36}$. Similar study done by Soleymani S et al. on Nigella sativa L. hydrogel (standardized based on thymoquinone) in a double-blinded randomized controlled clinical trial of 60 patients (each $n=30$ patients in treatment and placebo group) were randomly received Nigella sativa L. hydrogel, two times daily for 60 days. The Investigator's Global Assessment (IGA) grading score acne disability index (ADI) was recorded at the beginning and end of the study. The mean reduction in the IGA score was found to be $78 \%$ on the Nigella sativa L. treated group compared with the vehicle-treated one of 3.3\%, while reduced number of papules, comedones, and pustules were observed in the treatment group. Moreover, ADI (63.49\%) was decreased in the treatment group compared against $4.5 \%$ in the placebo groups. No adverse effect was noted $^{37}$.

\section{Eczema}

Yousefi et al. (2013) explored the curative potential of $2 \%$ ointment as topical application (twice/day for 4 weeks) in patients with hand eczema against eucerin and betamethasone. The scores obtained using Dermatology Life Quality Index and Hand Eczema Severity index showed that Nigella sativa L. ointment might have the equivalent efficacy as betamethasone, whereas it was found to be efficient when compared to eucerin $^{38}$.

\section{Cardio protective effect}

In a randomized clinical trial of menopausal women who were hyperlipidemic assigned to treatment $(n=19)$ or placebo groups $(\mathrm{n}=18)$, received either Nigella sativa $L$. or placebo for two months. Nigella sativa L. reported to improve lipid profiles of menopausal women with decreased total cholesterol, triglyceride, low density lipoprotein cholesterol and increased high density lipoprotein cholesterol greater than the placebo treatment elucidating the cardio protective effects of Nigella sativa L. ${ }^{39}$.

\section{Antihypertensive effect}

It has been accounted in a study that Nigella sativa L. oil showed optimistic results against hypertension through a decline in systolic blood pressure (SBP), asymmetric dimethylarginine, lactate dehydrogenase, plasma creatine kinase attenuation of oxidative injury and increase in tissue $\mathrm{Na}^{+} \mathrm{K}^{+}$ATPase activity with plasma nitric oxide level ${ }^{40}$.

\section{Gastroprotective effect}

A comparative study of 88 adult patients in Nigella sativa $L$. seeds against Helicobacter pylori ( $H$. pylori) using clarithromycin, amoxicillin, and omeprazole as a comparator was accessed $H$. pylori removal was observed in $82.6 \%$, $47.6 \%, 66.7 \%$ and $47.8 \%$ with triple therapy ${ }^{41}$. In an in vivo study, experimental animals were injected with Thymoquinone (10 and 20mg/kg), omeprazole (10 and 20 $\mathrm{mg} / \mathrm{kg}$ ) or their combination $(10 \mathrm{mg} / \mathrm{kg}$ ), pyloric ligation was carried out after $30 \mathrm{~min}$, and trailed consequently with ischemia for another 30min, then reperfused for $120 \mathrm{~min}$ 
leading to increased secretion of gastric acid, acid output, and pepsin, along with ulcer index whereas decreased the gastric mucin, glutathione, total nitric oxide, and superoxide dismutase. TQ at higher high dose level corrected the distorted parameters against omeprazole ${ }^{42}$.

\section{Neuroprotective effect}

The intragastric administration of Thymoquinone (20 mg/mL), Nigella sativa L. oil usage in aluminum trichloride (10 mg/kg day) and D-galactose (60 mg/kg day) induced neurotoxicity in rats showed a significant improvement of cognition, total antioxidant capacity and Superoxide dismutase while dipping the acetylcholinesterase activities, nitric oxide levels, malondialdehyde, tumor necrosis factor- $\alpha$ immunoreactivity, amplified brain derived neurotrophic factor and Bcell lymphoma-2 level. The assessment of memory function was calculated by Morris water maze test. This elaborated the use of Nigella sativa L. oil in neurodegenerative disorders ${ }^{43}$. Similar study done by Hosseini $\mathrm{M}$ et al. to investigate the effect of Hydro-alcoholic extract of Nigella sativa L. (NS) on memory power and its probable mechanisms in scopolamine (Sco) induced spatial memory injury in male Wistar rats ( $\mathrm{n}=$ 32) model using Morris water maze test saline was given to control group, instead of both NS extract and Sco. The Sco group received saline for two weeks, and then injected intraperitoneally by (Sco $2 \mathrm{mg} / \mathrm{kg}$ ). Sco and NS 200 and Sco and NS 400 groups were given by 200 or $400 \mathrm{mg} / \mathrm{kg}$ of NS (intraperitoneally) daily for a period of two weeks. Acetyl cholinesterase activity in the cortical tissues of the scopolamine group was considerably higher than the control group $(\mathrm{P}<0.01)$, while it was lower in the Sco+NS 200 and Sco+NS 400 groups. Pretreatment with extracts of Nigella sativa L. oil resulted in elevation of cortical total thiol content $(\mathrm{P}<0.01)$ and decline in cortical MDA concentration $(\mathrm{P}<0.01)$ compared against the Sco group ${ }^{44}$.

\section{Nephroprotective effect}

A vivo study elucidated the possible valuable effect of thymoquinone (TQ), the major active ingredient of the Nigella sativa L. seed oil, on lead induced renal antioxidant capacity impairment in male Wistar rats $(n=32)$ were randomized into a control group (received no treatment); a $\mathrm{Pb}$ group (exposed to 2,000 ppm of $\mathrm{Pb}$ acetate of imbibed water); a Pb-TQ group (Pb plus TQ (5 mg/kg/day); and a TQ group getting only TQ for a period of five weeks Result suggested that supplementation with TQ significantly enhanced the exaggerated antioxidant parameters ${ }^{45}$.

\section{Anticancer effect}

Nigella sativa $L$. essential oil nanoemulsion (NSEO-NE) (20-50 nm in diameter) in human breast cancer cells was tested by using modified methyl-thiazolyl-diphenyl tetrazolium bromide (MTT) assay as well as cellular uptake and nuclear morphological analyses. It was found that
Nigella sativa L. reduced the viable of Michigan Cancer Foundation-7 (MCF-7) breast cancer cells ${ }^{46}$. Furthermore, the cytotoxicity of thymoquinone on bladder cancer cells (T24 and 253J) was examined by MTT assay, colony formation assay and Annexin V-FITC/PI staining, while as a normal control, SV-HUC-1, SV-40 human uroepithelial cell streak was used . JC-1 staining was used for any change in mitochondrial membrane potential whereas mRNA expression and protein expression were examined by q PCR and western blotting assay and Caspase-3 activity by colorimetric assay. It was found that thymoquinone has a noteworthy cytotoxicity on the bladder cancer cells through the inhibition of their proliferation and induction of apoptosis. The protein changes of endoplasmic reticulum stress-related proteins (such as GRP78, CHOP, caspase 12), cytochrome c, Bax and Bcl-2 was due to the mitochondrial dysfunction and the endoplasmic reticulum stress pathway ${ }^{47}$.

\section{Anti-diabetic effect}

A randomized controlled clinical trial of previously diagnosed diabetes mellitus type (94 patients) who alienated randomly into three dose groups. Nigella sativa L. in capsule form were given orally in a dose of 1, 2 and 3 gm/day for a period of three months and then was assessed through the glycemic control measurement of fasting blood glucose, blood glucose level 2 hours postprandial, HbAlC (glycosylated hemoglobin), Serum C-peptide and changed body weight using the homeostatic model assessment. A dose of $2 \mathrm{gm}$ /day reduced the FBG, 2hPG, and HbA1 without any change in body weight. During the end of the 12 weeks treatment the blood parameter of $\mathrm{HbAlC}$ was declined by $1.52 \%(\mathrm{P}<0.0001)$ and Insulin resistance too, while B-cell function was improved $(\mathrm{P}<0.02)$ at 12 weeks of treatment. The use of Nigella sativa L. in a dose of $1 \mathrm{gm} /$ day also showed drifts in improvement in all the measured parameters. Still, no further increase was observed with the dose of $3 \mathrm{gm} / \mathrm{day}^{48}$.

\section{Anti-oxidant effect}

Nigella sativa L. oil (NSO) and thymoquinone prescription greatly ameliorated cisplatin (CP)-induced change on carbohydrate biotransformation and related defense system (enzymatic and nonenzymatic antioxidant) in the gastric mucosa of rat intestine. Rats were assigned into six groups, viz., control NSO, CP, CP+NSO, CP+TQ and TQ. The $\mathrm{CP}+\mathrm{NSO}$ and $\mathrm{CP}+\mathrm{TQ}$ animal groups were given NSO (2 $\mathrm{ml} / \mathrm{kg}$ BW, oral) and TQ (1.5 mg/kg BW, oral), daily for 14 days and successively treated with five repeated doses of CP (3 mg/kg BW, intraperitoneal), each fourth day for 20 days while continued in receiving NSO/TQ. Upon CP treatment there was a decline in the activities of brush border membrane (BBM) enzymes specifically while NSO or TQ to CP-treated rats prevented the decrease in BBM enzyme activities in the isolated brush border membrane vesicles (BBMV) along with mucosal homogenates ${ }^{49}$. 


\section{Effects on Male Infertility}

The role of alcoholic extract of Nigella sativa L. in vivo study of male rats on the fertility parameters, Pituitary-testicular axis hormones and Testosterone was evaluated. Rats were assigned into three groups viz. control, group A and group B of eight rats each. The control group received normal saline $(1 \mathrm{ml})$ and treatment groups (A, B) given doses of 200 and $400 \mathrm{mg} / \mathrm{kg}$ body weight of Nigella sativa seeds for 60 days daily. The treatment group found significant increase in testes and epididymidis weight, epididymal sperm reserve, daily sperm production, sperm count, blood testosterone concentration, LH and fertility index as compared to the control group ${ }^{50}$. A randomized, double-blind, placebocontrolled clinical trial was carried on infertile men $(n=68)$ of abnormal sperm morphology with less than of $30 \%$ or sperm counts lower than $20 \times 10(6) / \mathrm{ml}$ or less than type A and B motility of $25 \%$ and $50 \%$. The treatment group $(n=34)$ received $2.5 \mathrm{ml}$ Nigella sativa L. oil and control group $(\mathrm{n}=34)$ received $2.5 \mathrm{ml}$ liquid paraffin twice daily orally for 2 months. Results indicated the increase in sperm count (motility and morphology), pH, semen volume, and round cells were improved considerably in Nigella sativa L. oil treated group compared with control group after 2 months of therapy ${ }^{51}$.

\section{Anti-dyslipidemic and anti-obesity effect}

A recent study showed the effect of Nigella sativa L. oil and metformin on total body weight (TBW), mitochondrial membrane potential (MMP), semen parameters and serum testosterone in an obese animal mode of Wistar rats $(n=54)$ allocated into six groups with normal chow (NC), only high sugar diet (HSD), HSD and saline, HSD and metformin (75 $\mathrm{mg} / \mathrm{Kg} /$ day), HSD and Nigella sativa L. oil (200 mg/kg/day) or (NS200), HSD and Ns (400 mg/Kg/day) or (NS400) for a duration between 8 weeks to 14 weeks of dietary exposures. Results indicated that HSD increased total body weight $(\mathrm{P}=$ 0.001) and decreased the sperm concentration $(P=0.013)$ and progressive motility $(\mathrm{P}=0.009)$ compared to the normal chow group. NS200, Metformin and NS400 enhanced total body weight $(\mathrm{P}=0.006, \mathrm{P}=0.035$, and $\mathrm{P}=0.005)$ and testosterone $(\mathrm{P}<0.001)$ against the HSD saline group, whereas metformin and NS400 improved sperm concentration $(\mathrm{P}<0.001$ and $\mathrm{P}=0.049$, ) and mitochondrial membrane potential $(\mathrm{P}<0.001)$. It may be concluded that novel treatment options could be attributed to Metformin and Nigella sativa L. in obesity-induced infertility ${ }^{52}$.

\section{Immunomodulatory effect}

Black seed were inspected for their immune modulator action in BALB/C mice through the intraperitoneal inoculation of five doses of methanolic extract of Black seed which was found to increase the total WBC (white blood cells) count (up to $1.2 \times 10^{4}$ cells $/ \mathrm{mm}^{3}$ ) and Bone marrow cellularity and Spleen weight $(\mathrm{p}<0.01)$. The two groups of mice were immune suppressed with cyclophosphamide, the pretreated one with the black seed extracts significantly $(P<0.01)$ restore their struggle against deadly infection with the granulocyte-dependent and Candida albicans. These results showed the immune modulation activity of black seed, and may benefit therapeutically as well as prophylactic in opportunistic infections and in oncogenic cases as a supportive treatment ${ }^{53}$. Nigella sativa $\mathrm{L}$. oil is a natural radio protective agent against the immune suppression and oxidative effects of ionizing radiation in sixty male Wistar rats that divided into 4 groups (15 each), were considered as control- I rats, rats- II oral with Nigella sativa L. oil $(1 \mathrm{ml} / \mathrm{kg}$ BW/day) for 5 days/week, rats-III-whole body gamma irradiated rats with LD50/30 (4 Gray) and rats- IV daily given Nigella sativa L. oil then focused whole body to gamma irradiation, to find out the radioprotective potential of Nigella sativa L. crude oil against hemopoietic adverse actions of gamma irradiation. It was found that a reduction in hemolysin antibodies titers and delayed type hypersensitivity reaction, plasma total protein, globulin concentrations, diminution of lymphoid follicles of spleen and thymus gland of irradiated rats. Furthermore, significant increase was found in the malondialdehyde concentration ${ }^{54}$.

\section{Antidote}

There are two main modalities for managing these toxicities: chelation therapy to chelate toxic metals and antioxidant therapy to counteract oxidative stress. Hassan reported that black cumin extract $(25-200 \mu \mathrm{g} / \mathrm{mL})$ induced chelated iron (II) and scavenged hydroxyl radical $\left(\mathrm{OH}^{-}\right)$thereby promoting high DPPH radical scavenging activity ${ }^{55}$.

\section{Safety Evaluation of Black Cumin-Based Therapeutics}

Several studies have been dedicated to evaluate toxicological effects of black cumin and TQ were conducted ${ }^{56,57}$. It was evaluated whether Thymoquinone-nanostructured lipid carrier (TQ-NLC) showed any toxic effects, Yazan et al. observed that after TQ-NLC administrated in a dose of 25 $\mathrm{mg} / \mathrm{kg}$ by intravenous route, there was no noticeable alterations in the food intake, body weight, organ-to-body weight ratio, biochemical, hematological, and histopathological profile even though an inflammation was manifested at the site of inoculation in Sprague dawley rats tails ${ }^{56}$. In subacute toxicity evaluations, TQ has been found as an almost safe chemical ${ }^{58}$.

\section{CONCLUSION}

Medicinal plants are used as alternative treatment therapies in several diseases because of their reduced side effects and costs. In this review, published reports clearly advocated that Nigella sativa L. is an important medicinal plant in the traditional Unani system of medicine. The presence of thymoquinone mainly is responsible for its most of the medicinal properties. However, some studies have offered important results on the 
significant health benefits caused by other phytochemicals, such as thymohydroquinone, carvacrol, thymol, saponins, coumarins, flavonoids, phenolics, fixed oils alkaloids, saponins, sterol and $\alpha$-hederin suggesting that compounds further than TQ also warrant attention. Moreover, the presence of vitamins, myristic acid, proteins, fats, fiber, amino acids and some trace metals are also reported in the seeds particularly used as a neutraceutics. Numerous diseases, such as bronchitis, asthma, rheumatism, back pain, Cancer, gastrointestinal disorders, eczema, and hypertension etc. are mostly attributed towards antioxidant, anti-inflammatory, anticancer, immunomodulatory, antimicrobial, neuroprotective, cardioprotective, gastroprotective, antihypertensive, nephroprotective, hepatoprotective and antidiabetic properties ${ }^{59}$. Although kalonji and thymoquinone showed limited or no toxicity, this data was mostly preclinical studies based. Thus, a wide-ranging clinical human trial is warranted to validate the pharmacological and toxicological report for future medical use.

In conclusion, all the above-mentioned activities and findings robustly support the traditional Unani benefits of Nigella sativa L. as a food and medicinal herb. More clinical studies are warranted to explore the effectiveness of the diverse pharmacological active constituents for overcoming life threatening diseases such as various types of cancer, acquired immunodeficiency syndrome (AIDS), diabetes, cardiac diseases and the current corona virus (COVID-19) outbreak. Complimentary effects can be targeted from the various forms of Nigella sativa L. that include the seed, powder and oil for various health benefits in different preparations should be researched.

\section{Future perspectives}

The specific cellular and molecular objectives of various elements of Nigella sativa L., particularly of thymoquinone should be explored. This review article would help the researchers in examining and conducting auxiliary needed preclinical and clinical studies on the use of Nigella sativa L. for the treatment of wide array of diseases.

\section{Funding}

This review did not receive any specific grant from funding agencies in the public, commercial, or not-for-profit sectors.

\section{Conflicts of interest}

The authors declare no conflicts of interest.

\section{References}

1. Yimer EM, Tuem KB, Karim A, Ur-Rehman N, Anwar F. Nigella sativa L. (Black Cumin): A Promising Natural Remedy for Wide Range of Illnesses. Evidence Based Complementary and Alternative Medicine. 2019; 2019. doi: 10.1155/2019/1528635. PMID: 31214267, PMCID: PMC6535880.
2. Jiang T.A. Health benefits of culinary herbs and spices. Journal of AOAC International. 2019; 102(2):395-411. https://doi.org/10.5740/jaoacint.18-0418.

3. Mahmoud HS, Almallah AA, El-Hak HN, Aldayel TS, Abdelrazek HM, Khaled HE. The effect of dietary supplementation with Nigella sativa (black seeds) mediates immunological function in male Wistar rats. Scientific reports. 2021; 11(1):1-3. doi: https://doi.org/ 10.1038/s41598-021-86721-1

4. World Health Organization. Benchmarks for training in traditional /complementary and alternative medicine: benchmarks for training in Ayurveda. Geneva: World Health Organization; 2010. ISBN: 9789241599627, https://apps.who.int/iris/handle/10665/44352.

5. Antaki D. Tazkira oola al albab (Arabic).Vol I. New Delhi: CCRUM, Ministry of AYUSH. 2008: 441.

6. Tariq M. Nigella sativa seeds: folklore treatment in modern day medicine. Saudi Journal of Gastroenterolgy. 2008;14(3):105-6. doi: 10.4103/13193767.41725. PMID: 19568515; PMCID: PMC2702918

7. Gholamnezhad Z, Havakhah S, Boskabady MH. Preclinical and clinical effects of Nigella sativa and its constituent, thymoquinone: A review. Journal of ethnopharmacology.2016;190:372-86.

8. Ahmad MF, Ahmad FA, Ashraf SA, Saad HH, Wahab S, Khan MI, Ali M, Mohan S, Hakeem KR, Athar MT. An updated knowledge of Black seed (Nigella sativa Linn): Review of phytochemical constituents and pharmacological properties. Journal of herbal medicine. 2020:100404. https://doi.org/ 10.1016/ j.hermed.2020.100404.

9. Khan M.A. Muheet e Azam (Urdu). Vol. III. New Delhi: Central Council for Research in Unani Medicine (CCRUM); 2012: 382-5 (ISBN 978-3-319-19288-8) (eBook).

10. Ghani, M.N. Khazainul Advia (Urdu). New Delhi: Idara Kitab al Shifa; 2011: 154-8.

11. Ibn Al Baitar, IAK. Al Jami Li Mufradat Al Advia walAghzia (Urdu). Vol. I. New Delhi: Central Council for Research in Unani Medicine (CCRUM); 2006: 5154.

12. Khare C.P. Indian medicinal plants. Berlin/Heidelberg: Springer; 2007:49-50. ISBN978-0-387-70637-5 Springer-Verlag Berlin/Heidelberg.

13. Nadkarni A.K. Indian Materia Medica. Vol. I. Bombay: Bombay polular prakashan; 1995:854-7.

14. Kabeeruddin H.M. Makhzan al-Mufradat. Lahore: Siddiqui Publication; YNM:460-1. 
15. Anonymous. Standardization of single drugs of Unani Medicine. New Delhi: CCRUM; 1992:196- 201.

16. Anonymous. The Unani Pharmacopoeia of India. Part I. Vol. I. New Delhi: Government of India Ministry of Health \& Family Welfare; 2008:42-43.

17. Ahmad A, Husain A, Mujeeb M, Khan SA, Najmi AK, Siddique NA, Damanhouri ZA, Anwar F. A review on therapeutic potential of Nigella sativa: A miracle herb. Asian Pacific journal of tropical biomedicine. 2013;3(5):337-52. https://doi.org/ 10.1016/S2221-1691(13)60075-1.

18. Srinivasan K. Cumin (Cuminum cyminum) and black cumin (Nigella sativa) seeds: traditional uses, chemical constituents, and nutraceutical effects. Food quality and safety. 2018;2(1):1-6. Doi: https://doi.org/ 10.1093/fqsafe/fyx031.

19. Sahak MK, Kabir N, Abbas G, Draman S, Hashim NH, Hasan Adli DS. The role of Nigella sativa and its active constituents in learning and memory. EvidenceBased Complementary and Alternative Medicine. 2016 Jan 1;2016. Doi: https://doi.org/ 10.1155/2016/ 6075679 .

20. Mukhtar H., Mumtaz M.W., Tauqeer T., Raza S.A. Composition of Nigella sativa Seeds. In Black cumin (Nigella sativa) seeds: Chemistry, Technology, Functionality, and Applications. Springer, Cham; 2021: 45-57 https://doi.org/10.1007/978-3-030-48798-0_5

21. Ramadan M.F. Nutritional value, functional properties and nutraceutical applications of black cumin (Nigella sativa L.): an overview. International journal of food science \& technology. 2007;42(10):1208-18.doi: https://doi.org/10.1111/j.1365-2621.2006.01417.x.

22. Kirtikar K.R., Basu B.D. Indian Medicinal Plant. International Book Distributor, 1987;1(2):11-12.

23. Toppozada H.H., Mazloum H.A., El-Dakhakhny M. The antibacterial properties of the Nigella sativa l. seeds. Active principle with some clinical applications. The Journal of the Egyptian Medical Association. 1965;48:Suppl-187.

24. Bakathir HA, Abbas NA. Detection of the antibacterial effect of nigella sativa ground seeds with water. African Journal of Traditional, Complementary and Alternative Medicines. 2011;8(2).doi: 10.4314/ajtcam.v8i2.63203. Epub 2010 Dec 30. PMID: 22238497; PMCID: PMC3252685.

25. Rafati S, Niakan M, Naseri M. Anti-microbial effect of Nigella sativa seed extract against staphylococcal skin Infection. Medical journal of the Islamic Republic of Iran. 2014;28:42. PMID: 25405108; PMCID: PMC4219874.
26. Morsi N.M. Antimicrobial effect of crude extracts of Nigella sativa on multiple antibiotics-resistant bacteria. Acta Microbiologica Polonica. 2000;49(1):63-74. PMID: 10997492.

27. Salih Hamad Mohamad Aljabre, Mohamad Akram Randhawa, Naeem Akhtar, Omar Mohamad Alakloby, Abdulrahman Mohamad Alqurashi, Ali Aldossary. Antidermatophyte activity of ether extract of Nigella sativa and its active principle, thymoquinone. Journal of Ethnopharmacology. 2005; 101 (1-3):116119. https://doi.org/10.1016/j.jep.2005.04.002.

28. Ariamanesh H., Tamizi N., Yazdinezhad A., Salah S., Motamed N., Amanloo S. The Effectiveness of Nigella Sativa Alcoholic Extract on the Inhibition of Candida Albicans Colonization and Formation of Plaque on Acrylic Denture Plates: an In Vitro Study. Journal of Dentistry. 2019;20(3):171. doi: 10.30476/ DENTJODS.2019.44911. PMID: 31579691; PMCID: PMC6732174.

29. Salem M.L., Hossain M.S. Protective effect of black seed oil from Nigella sativa against murine cytomegalovirus infection. International journal of immunopharmacology. 2000;22(9):729-40.

30. Barakat E.M., El Wakeel LM, Hagag R.S. Effects of Nigella sativa on outcome of hepatitis C in Egypt. World journal of gastroenterology: WJG. 2013;19(16):2529.

31. Ali M, Eldahab MA, Mansour HA, Nigm A. Schistosoma mansoni: Antiparasitic effects of orally administered Nigella sativa oil and/or Chroococcus turgidus extract. Acta Biologica Hungarica. 2016;67(3):247-60. PMID: 27630048.

32. Okeola V.O., Adaramoye O.A., Nneji C.M., Falade C.O., Farombi E.O., Ademowo O.G. Antimalarial and antioxidant activities of methanolic extract of Nigella sativa seeds (black cumin) in mice infected with Plasmodium yoelli nigeriensis. Parasitology research. 2011;108(6):1507-12.doi: https://doi.org/10.1007/ s00436-010-2204-4.

33. Ab Rahman M.R., Abdul Razak F., Mohd Bakri M. Evaluation of wound closure activity of Nigella sativa, Melastoma malabathricum, Pluchea indica, and Piper sarmentosum extracts on scratched monolayer of human gingival fibroblasts. Evidence-Based Complementary and Alternative Medicine. 2014;2014.doi: https:// doi.org/1 0.1155/2014/190342.

34. Dwarampudi L.P, . Palaniswamy D., Muruganantham Nithyanantham PS. Antipsoriatic activity and cytotoxicity of ethanolic extract of Nigella sativa seeds. Pharmacognosy magazine. 2012;8(32):268.Doi: 10.4103/0973-1296.103650. 
35. Jawad A.H., Azhar I.Y., Khalil I.A.H. Evaluation of efficacy, safety and antioxidant effect of Nigella sativa in patients with psoriasis: a randomized clinical trial. $J$ Journal of Clinical and Experimental Investigations. 2014; 5(2),186-193. doi:10.5799/ ahinjs.01. 2014.02.0387.

36. Al-Harchan NA. Treatment of Acne Vulgaris with Nigella sativa oil lotion. the Iraqi postgraduate medical journal. 2010;9(2).

37. Soleymani S, Zargaran A, Farzaei MH, Iranpanah A, Heydarpour F, Najafi F, Rahimi R. The effect of a hydrogel made by Nigella sativa L. on acne vulgaris: A randomized double-blind clinical trial. Phototherapy Research. 2020;34(11):3052-62. doi: 10.1002/ptr.6739. PMID: 32548864.

38. Yousefi M, Barikbin B, Kamalinejad M, Abolhasani E, Ebadi A, Younespour S, Manouchehrian M, Hejazi S. Comparison of therapeutic effect of topical Nigella with Betamethasone and Eucerin in hand eczema. Journal of the European Academy of Dermatology and Venereology. 2013;27(12):1498504.doi:10.1111/jdv.12033.

39. Ibrahim RM, Hamdan NS, Mahmud R, Imam MU, Saini SM, Abd Rashid SN, Abd Ghafar SA, Ab Latiff L, Ismail M. A randomised controlled trial on hypolipidemic effects of Nigella Sativa seeds powder in menopausal women. Journal of translational medicine. 2014; 12(1):1-7.

40. Tasar N, Sehirli O, Yigner O, Leymanoglu S, Yegen B. Protective effects of Nigella sativa against hypertension-induced oxidative stress and cardiovascular dysfunction in rats. Marmara Pharmaceutical Journal. 2012;16(2):141-9.

41. Salem EM, Yar T, Bamosa AO, Al-Quorain A, Yasawy MI, Alsulaiman RM, Randhawa MA. Comparative study of Nigella Sativa and triple therapy in eradication of Helicobacter Pylori in patients with non-ulcer dyspepsia. Saudi journal of gastroenterology: official journal of the Saudi Gastroenterology Association. 2010;16(3):207 doi: doi: 10.4103/1319-3767.65201.

42. Magdy MA, Hanan EA, Nabila EM. Thymoquinone: Novel gastroprotective mechanisms. European journal of pharmacology. 2012;697(1-3):126-31.

43. Abulfadl YS, El-Maraghy NN, Ahmed AA, Nofal S, Badary OA. Protective effects of thymoquinone on Dgalactose and aluminum chloride induced neurotoxicity in rats: biochemical, histological and behavioral changes. Neurological research. 2018;40(4):324-33. doi: 10.1080/01616412.2018.1441776.
44. Hosseini M, Mohammadpour T, Karami R, Rajaei Z, Sadeghnia HR, Soukhtanloo M. Effects of the hydroalcoholic extract of Nigella sativa on scopolamineinduced spatial memory impairment in rats and its possible mechanism. Chinese journal of integrative medicine. 2015;21(6):438-44. doi: 10.1007/s11655014-1742-5.PMID: 24584756.

45. Mabrouk A, Cheikh HB. Thymoquinone ameliorates lead-induced suppression of the antioxidant system in rat kidneys. Libyan Journal of Medicine. 2016;11(1):31018.doi: https://doi.org/ 10.3402/ ljm.v11.31018.

46. Periasamy VS, Athinarayanan J, Alshatwi AA. Anticancer activity of an ultrasonic nanoemulsion formulation of Nigella sativa L. essential oil on human breast cancer cells. Ultrasonics sonochemistry. 2016;31:449-55. https://doi.org/ 10.1016/ j.ultsonch.2016.01.035

47. Zhang M, Du H, Huang Z, Zhang P, Yue Y, Wang W, Liu W, Zeng J, Ma J, Chen G, Wang X. Thymoquinone induces apoptosis in bladder cancer cell via endoplasmic reticulum stress-dependent mitochondrial pathway. Chemico-biological interactions. 2018;292:65-75. doi: 10.1016/j.cbi.2018.06.013. PMID: 29981725.

48. Bamosa AO, Kaatabi H, Lebdaa FM, Elq AM, AlSultanb A. Effect of Nigella sativa seeds on the glycemic control of patients with type 2 diabetes mellitus. Indian Journal of Physiology and Pharmacology. 2010;54(4):344-54. PMID: 21675032.

49. Shahid F, Farooqui Z, Khan AA, Khan F. Oral Nigella sativa oil and thymoquinone administration ameliorates the effect of long-term cisplatin treatment on the enzymes of carbohydrate metabolism, brush border membrane, and antioxidant defense in rat intestine. Naunyn-Schmiedeberg's archives of pharmacology. 2018;391(2):145-57.doi: 10.1007/s00210-017-14446.PMID: 29302711

50. Parandin R, Yousofvand N, Ghorbani R. The enhancing effects of alcoholic extract of Nigella sativa seed on fertility potential, plasma gonadotropins and testosterone in male rats. Iranian journal of reproductive medicine. 2012;10(4):355. PMID: 25246898; PMCID: PMC4165954

51. Kolahdooz M, Nasri S, Modarres SZ, Kianbakht S, Huseini HF. Effects of Nigella sativa L. seed oil on abnormal semen quality in infertile men: a randomized, double-blind, placebo-controlled clinical trial. Phytomedicine. 2014; 21(6):901-5. doi:10.1016/j. phymed. 2014.02.006. PMID: 24680621.

52. Leisegang K, Almaghrawi W, Henkel R. The effect of Nigella sativa oil and metformin on male seminal 
parameters and testosterone in Wistar rats exposed to an obesogenic diet. Biomedicine and Pharmacotherapy. 2021; 133:111085.

53. Ghonime M, Eldomany R, Abdelaziz A, Soliman $\mathbf{H}$. Evaluation of immunomodulatory effect of three herbal plants growing in Egypt. Immunopharmacology and immunotoxicology. 2011;33(1):141-5. doi: 10.3109/08923973.2010.487490. PMID: 20507215.

54. Assayed ME. Radioprotective effects of black seed (Nigella sativa) oil against hemopoietic damage and immunosuppression in gamma-irradiated rats. Immunopharmacology and immunotoxicology. 2010 Jun 1;32(2):284-96. doi: 10.3109/08923970903307552. PMID: 20105084.].

55. Hassan W, Noreen H, Khalil SU, Hussain A, Rehman S, Sajjad S, Rahman AU, da Rocha JB. Ethanolic extract of Nigella sativa protects Fe (II) induced lipid peroxidation in rat's brain, kidney and liver homogenates. Pakistan journal of pharmaceutical sciences. 2016;29(1): 231-237.
56. Yazan LS, Mohd Azlan SN, Zakarial Ansar FH, Gopalsamy B. Acute toxicity study of intravenous administration of thymoquinone-loaded nanostructured lipid carrier (TQ-NLC) in Sprague Dawley rats. Malaysian J Med Heal Sci. 2019;15(2):51-7.

57. Lou WP, Assaw SU, Lokman MA, Suhaimin NA, Yusof HM. Sub-acute toxicity of black seed (Nigella sativa) and honey mixture. Malays. Appl. Biol. 2018;47:11-8.

58. Mashayekhi-Sardoo H, Rezaee R, Karimi G. An overview of in vivo toxicological profile of thymoquinone. Toxin Reviews. 2018: 115-122.

59. Kooti W, Hasanzadeh-Noohi Z, Sharafi-Ahvazi N, Asadi-Samani M, Ashtary-Larky D. Phytochemistry, pharmacology, and therapeutic uses of black seed (Nigella sativa). Chinese journal of natural medicines. 2016;14(10):732-45. 